\title{
Validation of Fiber-Based Distributed Plasticity Approach for Steel Bracing Models
}

\author{
Alper Kanyilmaz ${ }^{\mathrm{a}^{*}}$ \\ ${ }^{a}$ Politecnico di Milano, Department of Architecture, Built Environment and Construction Engineering, Piazza Leonardo da Vinci, 32, \\ 20133 Milano, Italy
}

Received 11 December 2015; Accepted 31 December 2015

\begin{abstract}
Nonlinear analysis approach is not anymore limited only to research purposes, but becoming more popular as a tool that can be used during design, thanks to the increased efficiency of computer software and hardware. An accurately calibrated numerical model may simulate the behaviour of buildings in a quite realistic way, which helps designers understand better the performance of their structures. However, the feasibility of the nonlinear analysis approach is limited by the complexity of the numerical model, and the aim of any researcher or engineer is to obtain the most useful information in a reasonable amount of time. This study focuses on the validation of a simplified numerical modelling approach to simulate the nonlinear behaviour of steel bracings. The paper presents a comparison between two different modelling approaches; a refined finite element model using volumetric elements, and fiber-based model using beam elements with distributed plasticity. The numerical models calibrated with the experimental result from existing literature, reproduce the behaviour of cold formed square, and hot rolled open section steel elements under inelastic cyclic loading. The hysteresis loops obtained from two models show that the accuracy obtained by simpler fiber-element formulation is quite close to the more refined volumetric model. Finally, in order to assess the accuracy of the fiber-based modelling approach to estimate the nonlinear cyclic response of full-scale braced frame configurations, two real scale frames are analysed, and the results are compared with the results of the experiments performed on the test frames. In terms of computation time and accuracy, distributed plasticity model is much more efficient, and can be a good option to perform nonlinear analysis of multi-level buildings, which would be quite cumbersome with volumetric modelling approach. This study has been realized thanks to the research fund received from European commission with the contract MEAKADO RFSR-CT-2013-00022.
\end{abstract}

Keywords: Distributed Plasticity; Inelastic Cyclic Modelling; Fiber Based Beam Elements

\section{Introduction}

Accurate and reliable structural analysis procedures are strongly needed for a safe and economic structural design in seismic regions, where buildings experience large earthquake forces resulting in inelastic response of their structural elements. Advanced numerical modelling models, if well calibrated, provide reliable results to simulate complex civil engineering problems. The cost of numerical models can be very low compared to the experimental tests, however in order to rely on their results, the former should be rigorously validated and verified with the latter.

Traditionally, numerical modelling philosophy has been diversified for two purposes: for research and for design. For research, advanced nonlinear techniques have been the most effective to provide useful information on the realistic behaviour of materials and structures. On the other hand, for design, simplified linear modelling approach has been more common for their rapidity and reasonable estimations. The latter approach was indispensable for engineering offices, especially when the computer hardware and software had limited capacities. In recent years, thanks to the extremely increased efficiency of computer software and hardware, nonlinear analysis tools have become more common, and their utilization during design phase has become more feasible.

Continuum finite element modelling (CFEM) based on shell or solid elements is currently the most efficient numerical modelling method, which is able to reproduce, with a minimum margin of error, even complex phenomena such as

\footnotetext{
*Corresponding author: alper.kanyilmaz@polimi.it
} 
local buckling, distortion and changes in shape of the cross section [1][2][3][4][5]. However, this is not a common approach to study the global behaviour of multi-storey buildings subject to seismic actions, due to its inherent complexity, computational expense, and difficulty in preparing and calibrating the models. For this reason, the CFEM method is mostly used to study the response of individual profiles, or to represent details such as connection parts of structures.

To study the global nonlinear response of multi-story buildings, most common alternatives are concentrated plasticity and fiber-based modelling approaches. Concentrated plasticity approach limits the inelastic deformations in individual parts of the structural system (as plastic hinges) with the rest of the structure remaining elastic. This method better captures the nonlinear response of members through calibration using test data on moment-rotation or hysteresis curves. Fiber-based modelling on the other hand, distributes plasticity by numerical integrations through the member cross sections and along the member length, and with a "plane sections remain plane" assumption [6][7]. Uniaxial material models are used to capture the nonlinear hysteretic axial stress-strain characteristics in the element cross sections. Fibers are numerically integrated over the cross section to monitor the axial force and moments, incremental moment-curvature and axial force-strain relations. The cross section parameters are numerically integrated at several sections along the member length, using displacement or force interpolation functions. This approach allows performing nonlinear analysis considering both geometric and material nonlinearity, within a time much more limited than a 3D continuum finite element analysis [8][9]. However, using this approach local behaviour such as degradation due to local buckling is difficult to capture without sophisticated models. Fiber-based modelling approach with distributed plasticity (DPE) offers a good compromise in terms of accuracy and computational time to model hysteresis behaviour of steel struts. Application example of this approach has been presented in several research articles for braced and moment-resisting frames [10] [11].

Simulation of the cyclic behaviour of bracing members with fiber-based approach has been the subject of investigation by several researchers [11][12][13], who developed advanced open-source numerical models capable of simulating the flexural rigidity of bracing connections, low-cycle fatigue and local buckling phenomena. Although it has been proved that these models can estimate the hysteretic behaviour of bracings to a high degree of speed and accuracy, their application in engineering offices for design purposes may not be practical, due to their high level of complexity.

This paper shows the degree of accuracy of a fiber-based modelling approach, using commercial software [15]. The paper is organized into three parts. First, a three dimensional finite element model has been calibrated with the results of experimental data that comes from the cyclic tests previously performed on cold-formed square elements. During the calibration, the main changing parameter was the slenderness of the steel struts, which permitted to identify the accuracy of the model estimating the hysteresis behaviour of the struts with and without the effect of local buckling phenomena. Then, a simpler fiber-based model has been developed on the selected case study, and the results of inelastic cyclic analysis have been compared with the results of the complex finite element model. Besides the square element, the cyclic behaviour of an open section has also been simulated, and comparisons have been provided. Finally, the validation study has been concluded with the numerical simulation of two real-scale test frames, in order to assess the accuracy of the proposed modelling approach to estimate the nonlinear cyclic response of full-scale braced frame configurations. The results of numerical model and experimental tests have been compared presenting the advantages and drawbacks of the fiber-based numerical modelling approach.

\section{Modelling of cyclic behaviour of bracing elements}

Inelastic deformation of bracing elements is the main parameter affecting the seismic performance of braced frames during a seismic event. In order to explore accurate and time efficient modelling ways for the numerical simulation of inelastic behaviour of steel bracings under cyclic loading, validation studies have been performed based on experimental data and refined finite element models. Validation has been done in two steps:

i) Numerical model of various steel struts made of cold formed square hollow sections have been developed and calibrated with the inelastic cyclic load tests in literature [15]. Continuum finite element modelling approach is used (CFEM);

ii) Fiber based distributed plasticity modelling approach has been validated against calibrated continuum finite element model of both square and open section steel elements (DPE).

Experimental data comes from several cyclic tests previously performed on cold-formed square and rectangular hollow steel section bracing elements, according to the provisions of the ECCS (1986) [17]. Fifteen specimens have

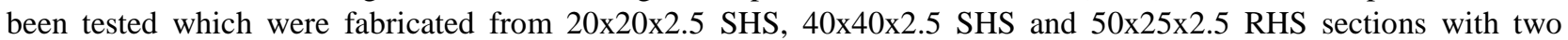
different lengths: intermediate $(1100 \mathrm{~mm})$ and long $(3300 \mathrm{~mm})$. Table 1 shows the physical properties of Model 1 (intermediate length) and Model 2 (long length) steel struts of 40x40x2.5 SHS cross- sections that are used in this study. The selected models have the same cross-sectional properties, and mainly differ in their slenderness ratios $\overline{(\lambda)}$. Change of this parameter results in different yield and ultimate loads $\left(\mathrm{F}_{\mathrm{y}}\right.$ and $\left.\mathrm{F}_{\max }\right)$ and deformations $\left(\delta_{\mathrm{y}}\right.$ and $\left.\delta_{\max }\right)$ 
during the cyclic tests. A general layout of the test specimens is shown in Figure 1.

Table 1. Test program and material properties Error! Reference source not found.

\begin{tabular}{|c|c|c|c|c|c|c|c|}
\hline Test ID & Section Size & $\bar{\lambda}$ & $d / t$ & $\begin{array}{l}\mathrm{F}_{\mathrm{y}} \\
\mathrm{kN}\end{array}$ & $\begin{array}{l}\delta_{\mathrm{y}} \\
\mathrm{mm}\end{array}$ & $\begin{array}{l}\mathrm{F}_{\max } \\
\mathrm{kN}\end{array}$ & $\begin{array}{l}\delta_{\mathrm{u}} \\
\mathrm{mm}\end{array}$ \\
\hline \multicolumn{8}{|l|}{ Series1 } \\
\hline CyIS1 & $40 \times 40 \times 2.5$ & 0.4 & 13.1 & 100.4 & 2.4 & 112.9 & 20.7 \\
\hline CyIS2 & $40 \times 40 \times 2.5$ & 0.4 & 13.1 & 101.5 & 2.4 & 112.4 & 17.8 \\
\hline CyIS3 & $20 \times 20 \times 2.0$ & 0.9 & 6.7 & 26.0 & 1.2 & 45.4 & 35.3 \\
\hline CyIS4 & $20 \times 20 \times 2.0$ & 0.9 & 6.7 & 29.8 & 1.1 & 46.0 & 22.6 \\
\hline CyIS5 & $50 \times 25 \times 2.5$ & 0.6 & 17.1 & 78.1 & 1.6 & 111.5 & 23.0 \\
\hline CyIS6 & $50 \times 25 \times 2.5$ & 0.6 & 17.1 & 83.1 & 1.8 & 111.5 & 21.8 \\
\hline \multicolumn{8}{|l|}{ Series2 } \\
\hline CyLS1 & $40 \times 40 \times 2.5$ & 1.3 & 12.9 & 123.1 & 4.3 & 143.9 & - \\
\hline CyLS2 & $40 \times 40 \times 2.5$ & 1.3 & 12.9 & 124.1 & 4.4 & 143.8 & - \\
\hline CyLS3 & $40 \times 40 \times 2.5$ & 1.3 & 12.9 & 126.5 & 5.7 & 142.5 & - \\
\hline CyLS4 & $20 \times 20 \times 2.0$ & 3.2 & 6.5 & 63.1 & 7.0 & 70.2 & 16.0 \\
\hline CyLS5 & $20 \times 20 \times 2.0$ & 3.0 & 6.0 & 64.4 & 7.9 & 69.3 & 15.2 \\
\hline CyLS6 & $20 \times 20 \times 2.0$ & 3.0 & 6.0 & 63.6 & 6.0 & 72.3 & 16.7 \\
\hline CyLS7 & $50 \times 25 \times 2.5$ & 1.9 & 17.3 & 99.4 & 4.6 & 117.7 & - \\
\hline CyLS8 & $50 \times 25 \times 2.5$ & 2.2 & 16.9 & 162.6 & 7.3 & 187.7 & - \\
\hline CyLS9 & $50 \times 25 \times 2.5$ & 2.2 & 16.9 & 165.4 & 7.0 & 190.1 & - \\
\hline
\end{tabular}
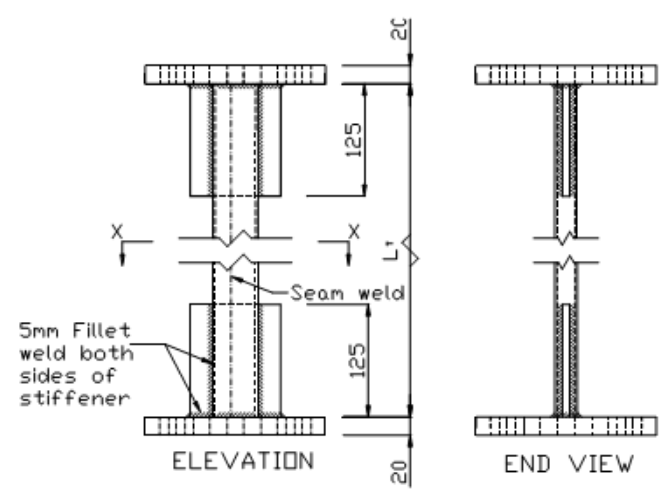

Cross section:

$\mathrm{E}=$

Poisson's ratio:

$\mathrm{f}_{\mathrm{y}}=$

$\mathrm{f}_{\mathrm{u}}=$

$\varepsilon_{\mathrm{u}}=$

Element length (model 1)

Element length (model 2) 40x40x2.5 mm

$210000 \mathrm{MPa}$

0.3

$343 \mathrm{MPa}$

$393 \mathrm{MPa}$

0.15

$1100 \mathrm{~mm}$

$3300 \mathrm{~mm}$

\section{b. Material properties}

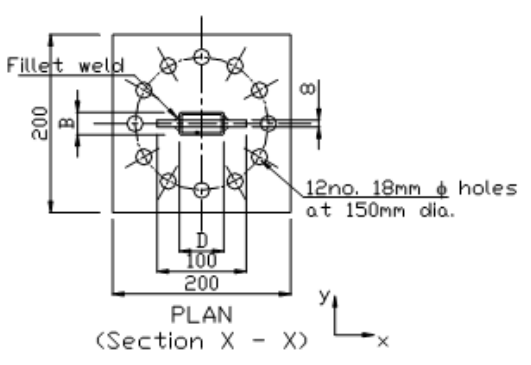

b. Top view

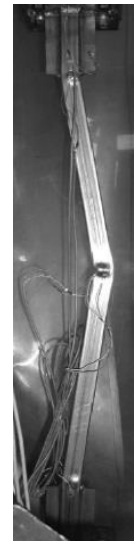

c. During tests

a. Elevation and end view

Figure 1. Test specimen [15]

Finite element models of this article have been developed with software package (ABAQUS) [18]. ABAQUS is a general-purpose finite element modelling package developed for the numerical analysis of a variety of mechanical problems, including nonlinear static and dynamic structural analysis. Its features lets user simulate several nonlinearities such as plasticity, large deformations, hardening, and second order effects can in the numerical solution of complex structural engineering problems.

The models are made of three-dimensional brick elements with 8-nodes (fully integrated). Each node has three translational and three rotational degrees of freedom, simulating the large deflection, large strain, plasticity features. Numerical model takes into account both geometrical (large deformation and strain) and material nonlinearity (elastoplastic behaviour with Von Mises Criteria). Kinematic type hardening is considered. The formulation of the elements accounts for finite strains and rotations, and allows for changes in thickness with deformation, and capable of simulating the shift of the yield surface to account for the Bauschinger effect [19]. Each step of the analysis involves automatically defined increments. Within each increment, iterations are used to find the equilibrium solution. At the end of each increment, the solution achieves equilibrium with a specified tolerance.

Calculation procedure is composed of two steps:

i) Buckling modes obtained from linear buckling analysis,

ii) Then inelastic cyclic analysis has been performed considering an initial imperfection based on first and/or second buckling mode shape.

One end of the steel strut is fully fixed, while the other end is fully fixed except for the axial degree of freedom, to which the cyclic displacement loads are applied (Figure 2). This configuration simulates the real boundary conditions that are applied during the tests. 


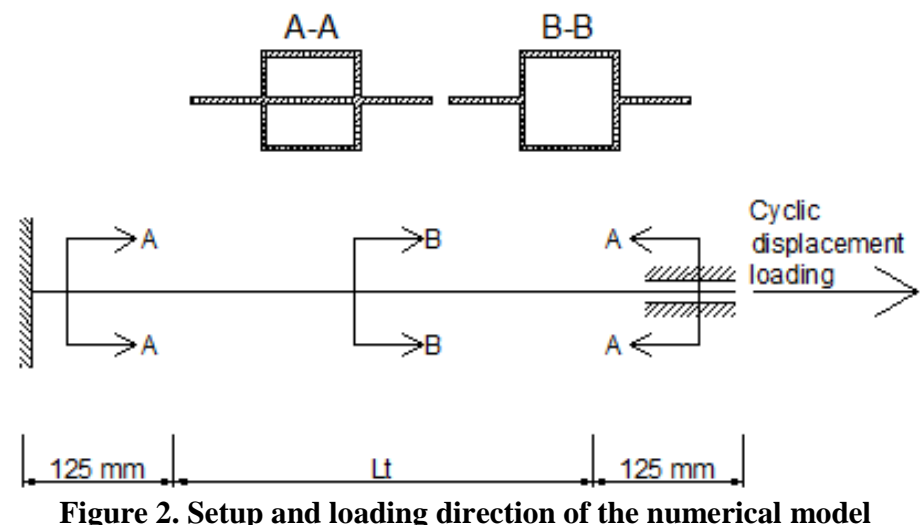

For element with $1100 \mathrm{~mm}$ length (model 1) and $3300 \mathrm{~mm}$ length (model 2), cyclic displacements are applied with same amplitudes but with different number of cycles (Table 2).

Table 2. Loading procedure

\begin{tabular}{|l|l|}
\hline \multicolumn{2}{|l|}{ Model 1 (1100 mm) } \\
\hline one cycle & $+/-0.625 \mathrm{~mm}$ \\
\hline one cycle & $+/-1.25 \mathrm{~mm}$ \\
\hline one cycle & $+/-2.5 \mathrm{~mm}$ \\
\hline Three cycles & $+/-5 \mathrm{~mm}$ \\
\hline Three cycles & $+/-10 \mathrm{~mm}$ \\
\hline Three cycles & $+/-15 \mathrm{~mm}$ \\
\hline Three cycles & $+/-20 \mathrm{~mm}$ \\
\hline Three cycles & $+/-25 \mathrm{~mm}$ \\
\hline
\end{tabular}

\begin{tabular}{|l|l|}
\hline \multicolumn{2}{|l|}{ Model 2 (3300 mm) } \\
\hline one cycle & $+/-0.625 \mathrm{~mm}$ \\
\hline one cycle & $+/-1.25 \mathrm{~mm}$ \\
\hline one cycle & $+/-2.5 \mathrm{~mm}$ \\
\hline Three cycles & $+/-5 \mathrm{~mm}$ \\
\hline Three cycles & $+/-10 \mathrm{~mm}$ \\
\hline Three cycles & $+/-15 \mathrm{~mm}$ \\
\hline Three cycles & $+/-20 \mathrm{~mm}$ \\
\hline Three cycles & $+/-25 \mathrm{~mm}$ \\
\hline Three cycles & $+/-30 \mathrm{~mm}$ \\
\hline Three cycles & $+/-40 \mathrm{~mm}$ \\
\hline
\end{tabular}

Mesh properties are shown in Figure 3. In areas where local buckling is expected, refined meshes were used (at the ends and at the center of the member). The size and the length of refined mesh areas are decided after a sensitivity analysis. To be able to trigger the element's buckling during the inelastic cyclic analysis, initial imperfections have been incorporated in the numerical model of bracing elements. For this purpose, a linear buckling analysis has been performed, and inelastic cyclic analysis has started on the base of the deformed shapes obtained from the first and/or second linear buckling modes.

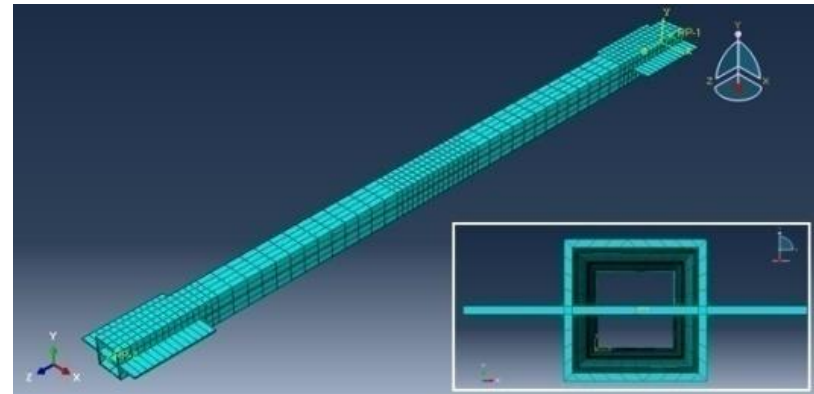

a. Tube $1100 \mathrm{~mm}: 2376$ linear hexahedral, 444 linear wedge elements (At the mid-height and at end of the tube, for a length of $160 \mathrm{~mm}$, mesh is denser)

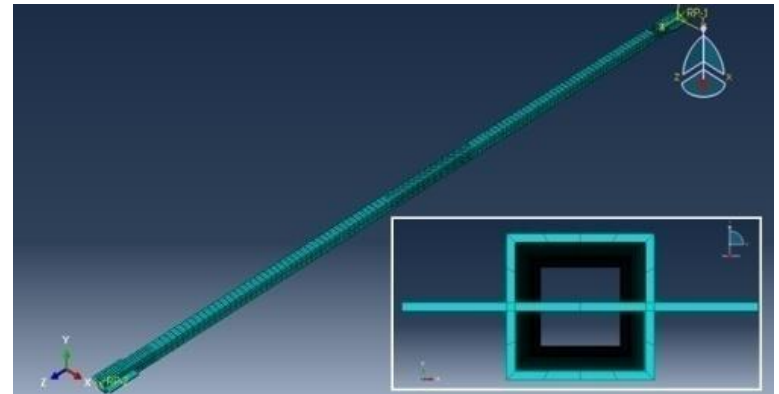

b. Tube $3300 \mathrm{~mm}$ : 5340 linear hexahedral elements (At the mid-height and at end of the tube, for a length of $480 \mathrm{~mm}$ and $225 \mathrm{~mm}$, mesh is denser)

Figure 3. Mesh model 1 and model 2

In Figure 4 and Figure 5, first two linear buckling mode shapes are shown. According to the results of the experimental studies, only first mode deformed shape has been used in model 1, and both first and second mode shapes have been used for the model 2. Initial imperfection value is considered as L/150 according to EN1998-1- 
1 [20]; however for the longer element convergence could be obtained by a larger value (L/120).

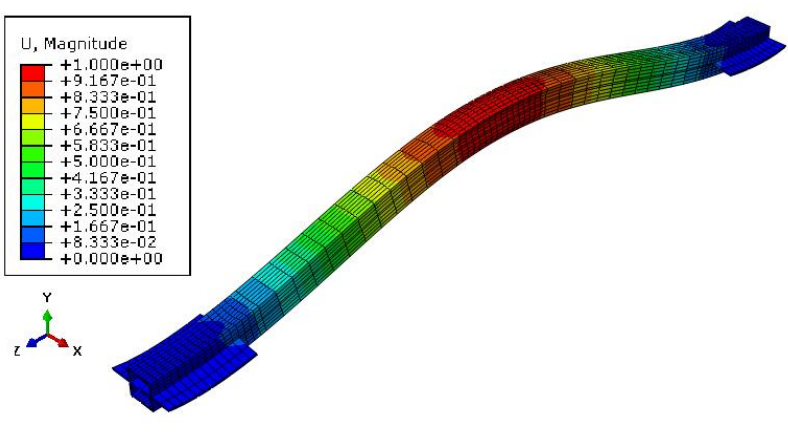

a. First global buckling mode shape

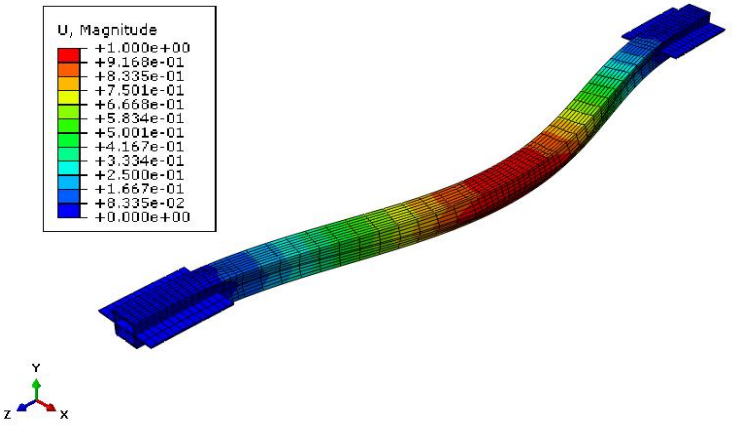

b. Second global buckling mode shape

Figure 4. First and buckling mode shapes - model 1

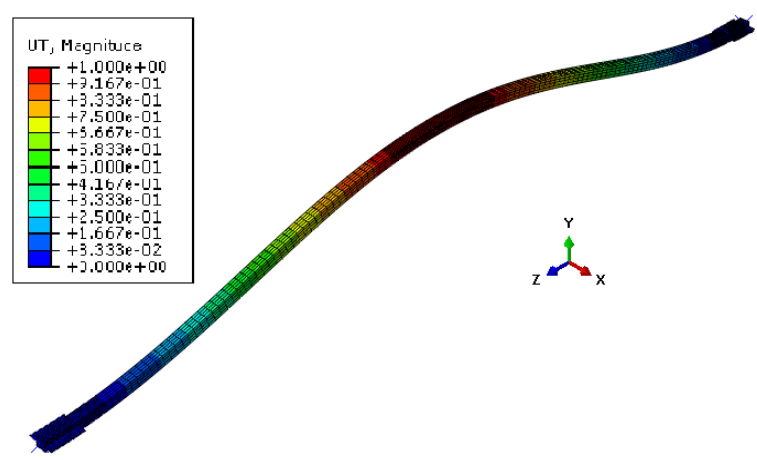

a. First global buckling mode shape

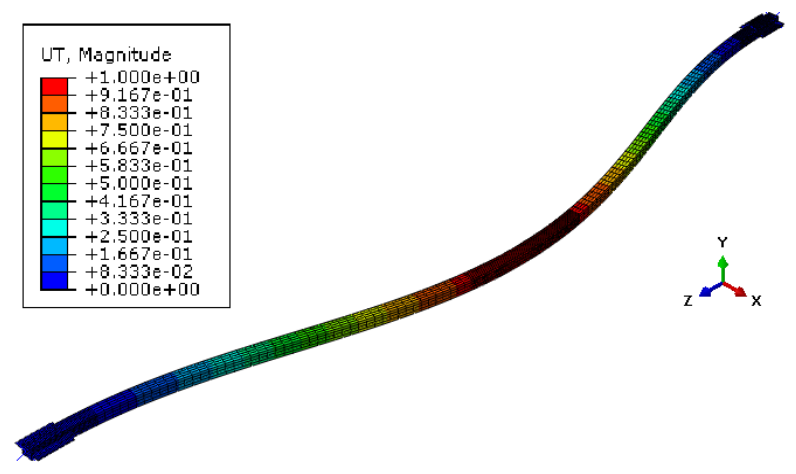

b. Second global buckling mode shape

Figure 5. First and second buckling mode shapes - model 2

Both numerical models satisfactorily estimate the critical buckling load, which can be seen in Table 3, showing a comparison between the values obtained from linear buckling analysis and Euler buckling calculations. Based on these positive indications, simulation of the inelastic behaviour of the models has been performed, and its results have been compared with the results of the experimental tests.

Table 3. Comparison of critical buckling loads obtained numerically and analytically

\begin{tabular}{|l|c|c|}
\cline { 2 - 3 } \multicolumn{1}{c|}{} & Tube $1100 \mathrm{~mm}$ & Tube $3300 \mathrm{~mm}$ \\
\hline Numerical model & $573.75 \mathrm{KN}$ & $66.03 \mathrm{KN}$ \\
\hline Euler critical load & $563.20 \mathrm{KN}$ & $62.58 \mathrm{KN}$ \\
\hline
\end{tabular}

Figure 6 shows the plastic deformations concentrated at the beam ends and at the centre of the braces, which was the case during the experimental tests.

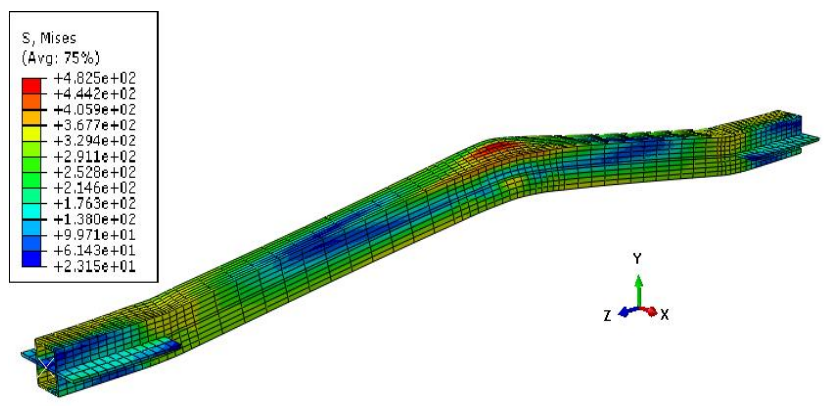

Deformed shape of tube1100 at ultimate load

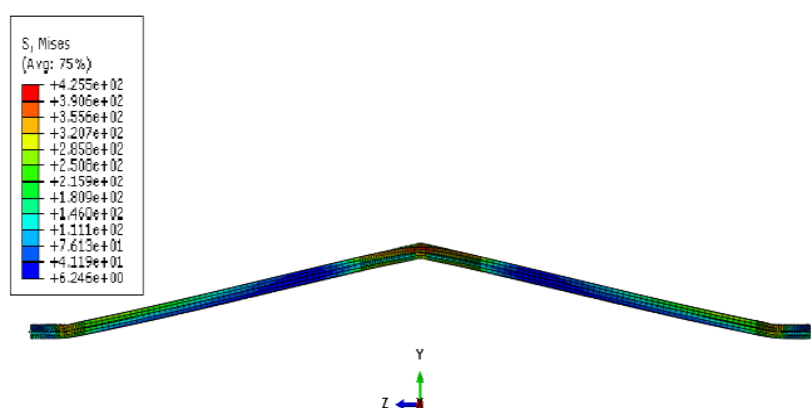

Deformed shape of tube3300 at ultimate load

Figure 6. Deformed shape of tube elements under ultimate load 
A good agreement between numerical model and experimental results has been obtained, except for the last three cycles of the displacement loading due to impossibility to reproduce local buckling fractures experienced by test specimens (Figure 7). In the numerical simulation of both models, after the first buckling in compression takes place, compressive strength decreases because of plastic hinges formed at the centre of the brace and next to the end plates. Then the compressive strength continues to degrade due to Baushinger effect.

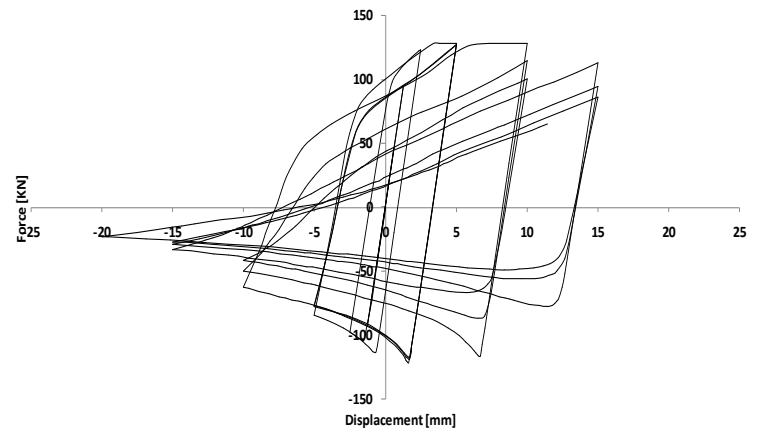

a. Numerical model (Abaqus)

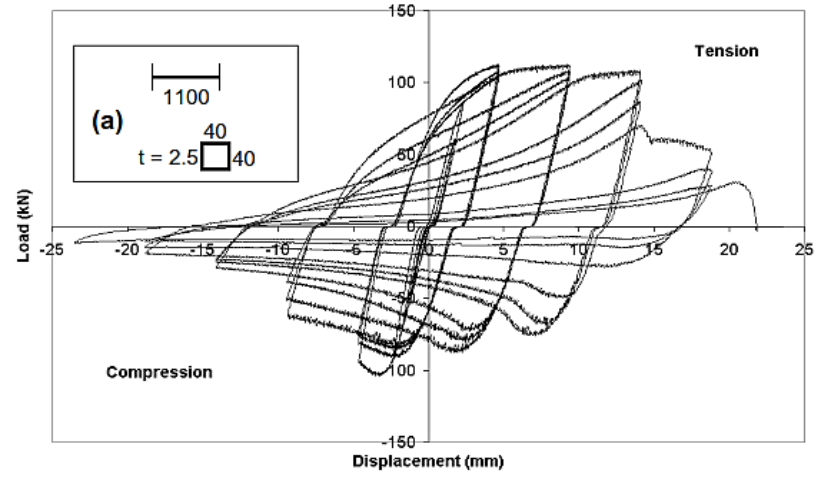

b. Experimental result

Figure 7. Load-displacement curve - Model 1

In the case of model 2 , the convergence between the experimental and numerical curve is much better, since no local buckling fracture occurred during the test (Figure 8). The decrease in the global tensile and compression resistance is well visible in the numerical curve, with the exception of the last cycle. The maximum compression force recorded by the numerical model is $57.49 \mathrm{KN}$, while the experimental value is $52.30 \mathrm{KN}$. Maximum tensile force recorded by the numerical model is $127.20 \mathrm{KN}$, while the experimental value is $143.80 \mathrm{KN}$. Furthermore, in agreement with the experimental results, the numerical model provides global biaxial instability (Figure 9).

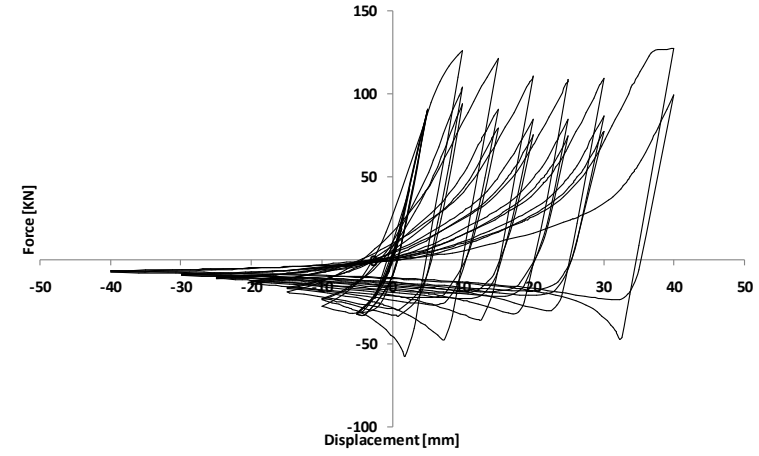

a. Numerical model (Abaqus)

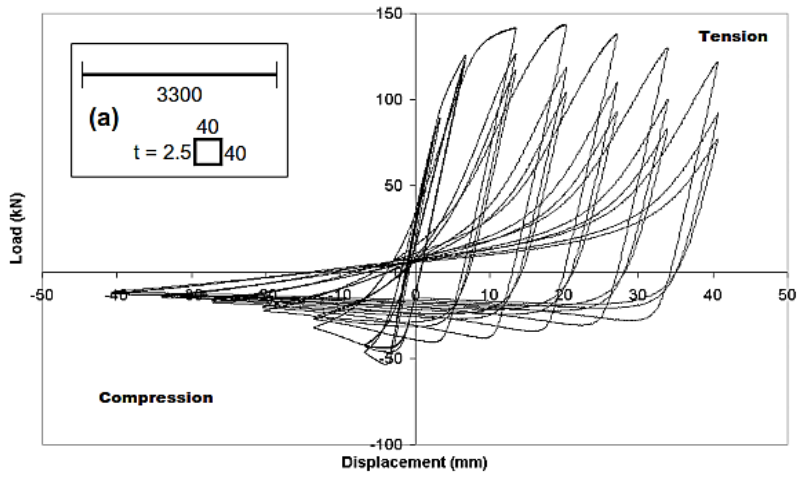

b. Experimental result

Figure 8. Load-displacement curve - Model 2

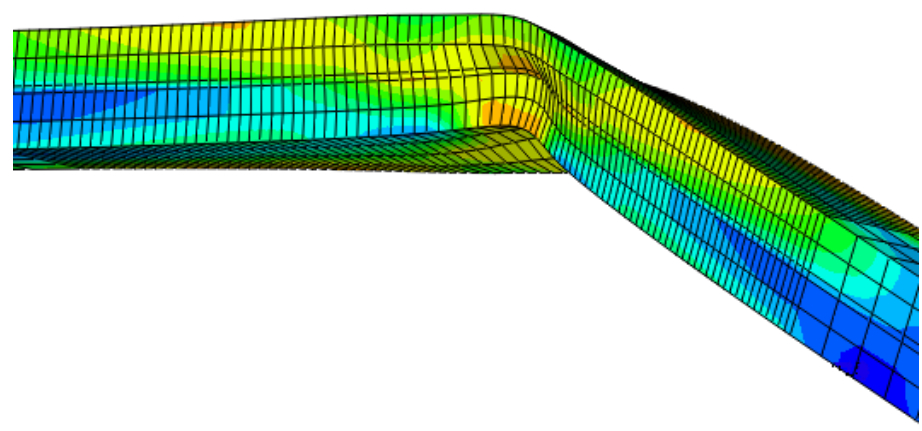

Figure 9. Biaxial instability model 2

In Table 4, comparisons are shown in terms of inelastic buckling and ultimate tensile loads according to numerical model, Eurocode 3, and experimental results. In general, it is seen that numerical simulation of more slender element gives better results. 
Table 4. Comparison of major loading limits between numerical analysis, experiments and Eurocode

\begin{tabular}{|c|c|c|c|}
\cline { 2 - 3 } \multicolumn{2}{|c|}{} & Tube 1100mm & Tube 3300mm \\
\hline \multirow{3}{*}{ Inelastic Buckling Load } & Numerical model & $121.66 \mathrm{KN}$ & $57.49 \mathrm{KN}$ \\
\cline { 2 - 4 } & Eurocode & $109.85 \mathrm{KN}$ & $43.51 \mathrm{KN}$ \\
\cline { 2 - 4 } & Experiment & $105.50 \mathrm{KN}$ & $52.30 \mathrm{KN}$ \\
\hline \multirow{3}{*}{ Ultimate tensile load } & Numerical model & $128.46 \mathrm{KN}$ & $127.20 \mathrm{KN}$ \\
\cline { 2 - 4 } & Eurocode & $147.38 \mathrm{KN}$ & $147.38 \mathrm{KN}$ \\
\cline { 2 - 4 } & Experiment & $112.40 \mathrm{KN}$ & $143.80 \mathrm{KN}$ \\
\hline
\end{tabular}

\section{Validation of fiber based distributed plasticity approach}

At this section, comparisons are shown between the results obtained from a CFEM model developed using Abaqus, and a fiber-based model developed using (Strand7) [15] (Figure 10). In fiber-based distributed plasticity approach, each element is divided into several cross sections along the member length, which are further subdivided into fibers (mono-dimensional elements with nonlinear elastic constitutive law). Assuming that plane section remains plane (sections need to be normal to the axis of the element), the strain in each fiber is calculated from centroidal section strain and curvature, then the stresses and modulus of fibers are calculated from the previous strain values. By integrating the response of the fibers, the constitutive relation of the cross section is obtained, which are then integrated along the member length, using appropriate interpolation functions Figure 10.b.

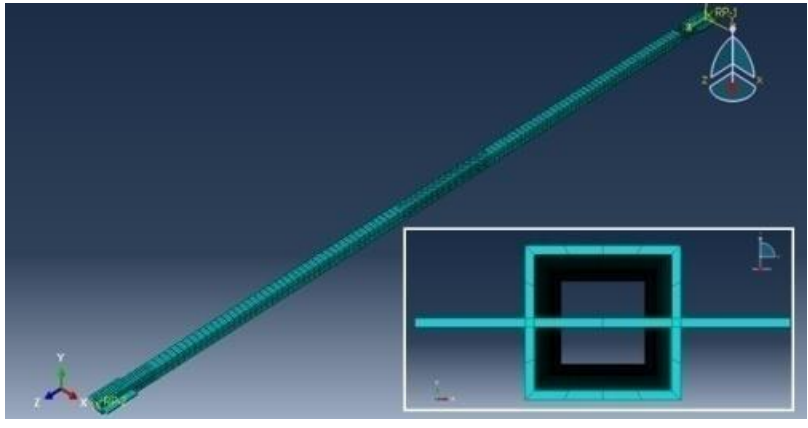

a. CFEM approach

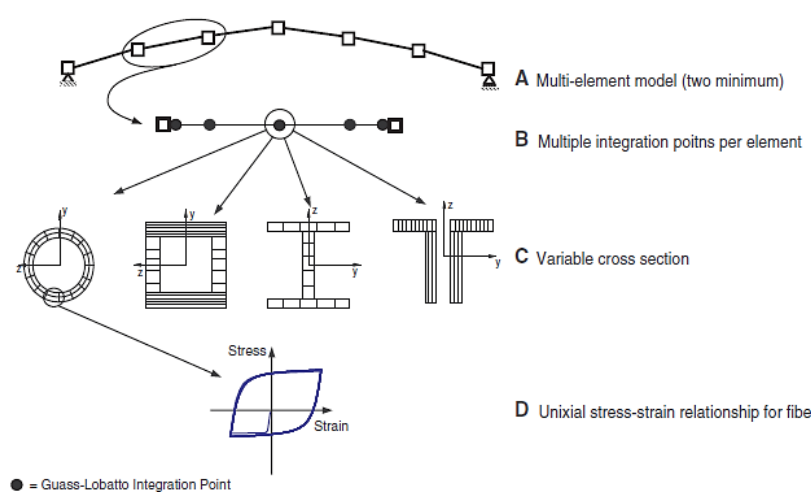

b. Fiber based distributed plasticity approach [15]

Figure 10. CFEM vs Fiber based approach

Linear buckling analysis results are very similar (Figure 11). After the linear validation of fiber-based model, hysteresis response of the model 2 has been compared, and then the same comparison has been made for an open section.

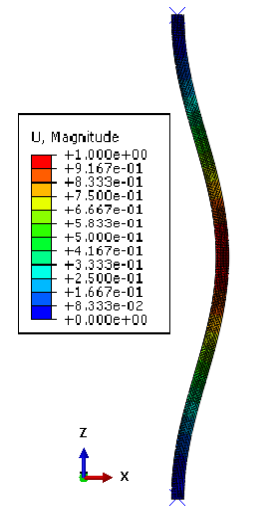

Abaqus $1^{\circ}$ buckling mode: $66 \mathrm{kN}$

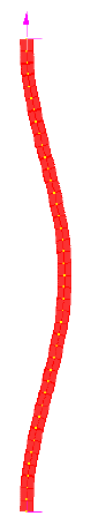

Straus $71^{\circ}$ buckling mode: $67 \mathrm{kN}$

Figure 11. Comparison in terms of $1^{\text {st }}$ linear buckling mode 
From the comparison of two hysteresis curves obtained from an inelastic cyclic analysis, it is evident how DPE model is able to reproduce the nonlinear response of the profile under cyclic loading (Figure 12). Both models show a gradual reduction in the maximum compression resistance at later cycles, which is in line with the actual behaviour of the specimens observed during the experiments performed.

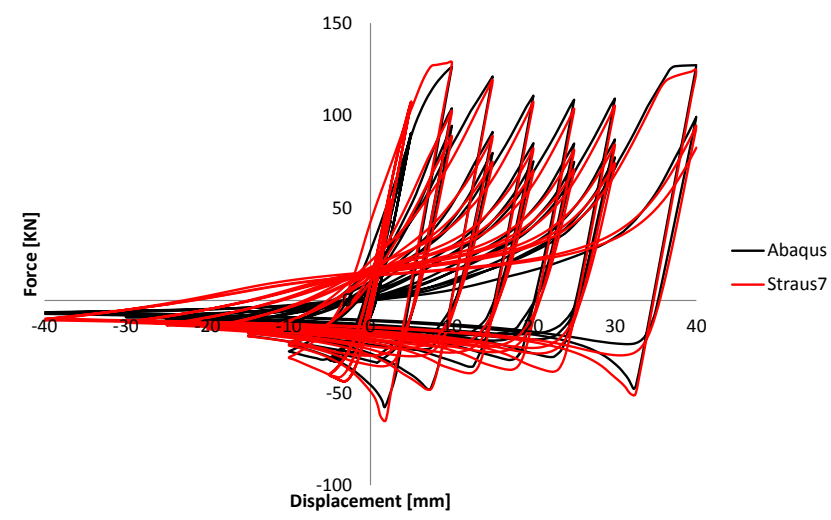

Figure 12. Comparison of hysteretic response of two modelling approaches

Maximum and minimum values achieved by the two curves are also coincident. However, in terms of dissipated energy, represented by the area enclosed by the hysteresis curves, there is a slight difference between the two models. DPE model dissipates slightly more, since DPE modelling cannot capture local instabilities that can be captured by a refined FE model with shell elements. Yet, considered the time required for the analysis and the satisfactory accuracy of DPE model, it can be concluded that the modelling with distributed plasticity (DPE) represents a good compromise between the validity of the results and analysis time.

Another comparison has been made with an open section. A DUPE100 section with 4310mm length has been analysed. Boundary conditions are fixed on both ends for all degrees of freedom, except the axial translational degree of freedom in one end to impose the axial displacement. Material properties are shown in Table 5.

Table 5. Material properties

\begin{tabular}{|l|l|}
\hline Cross section: & DUPE100 \\
\hline E: Young's modulus & $210000 \mathrm{MPa}$ \\
\hline v: Poisson coefficient & 0,30 \\
\hline $\mathrm{f}_{\mathrm{y}}:$ yield strength & $343 \mathrm{MPa}$ \\
\hline $\mathrm{f}_{\mathrm{u}}:$ ultimate strength & $393 \mathrm{MPa}$ \\
\hline$\varepsilon_{\mathrm{u}}:$ ultimate strain & 0.15 \\
\hline
\end{tabular}

Linear buckling analysis give similar results (Figure 13).

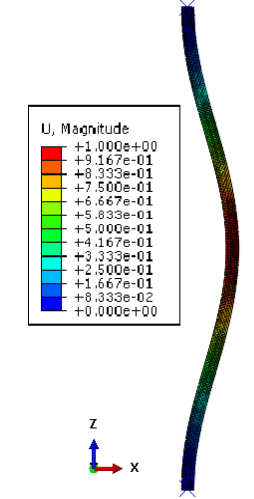

a. Abaqus $1^{\circ}$ buckling mode: $720 \mathrm{kN}$

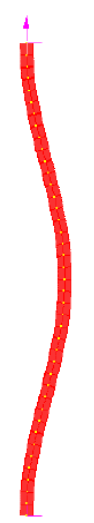

b. Straus $71^{\circ}$ buckling mode: $740 \mathrm{kN}$

Figure 13. Comparison of two approaches in terms of critical buckling load 
Also in this case, results of DPE model and CFEM model are very similar. The observations made in the calibrated tube model are valid also for this case (Figure 14).

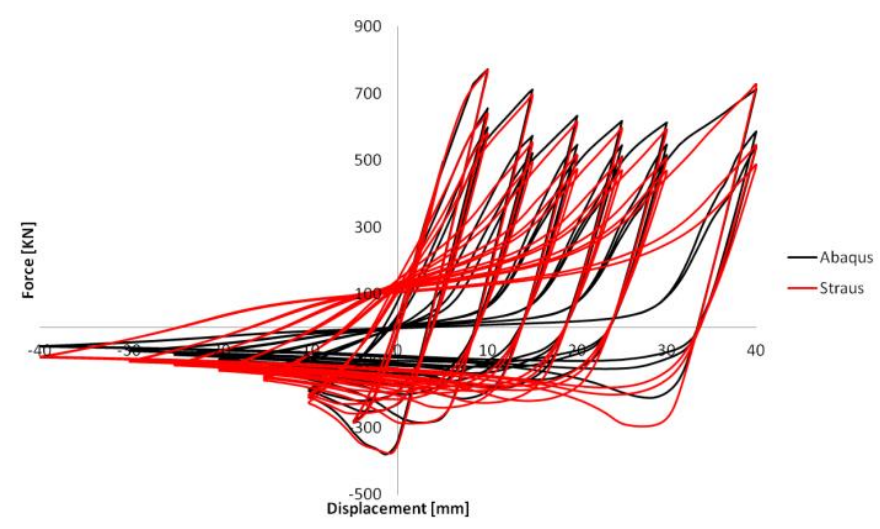

Figure 14. Comparison of hysteretic response of two modelling approaches

Small differences between the behaviour of the two models is due to the fact that local instabilities that cannot be captured by fiber-based approach, the examples of which are shown in in Figure 15.
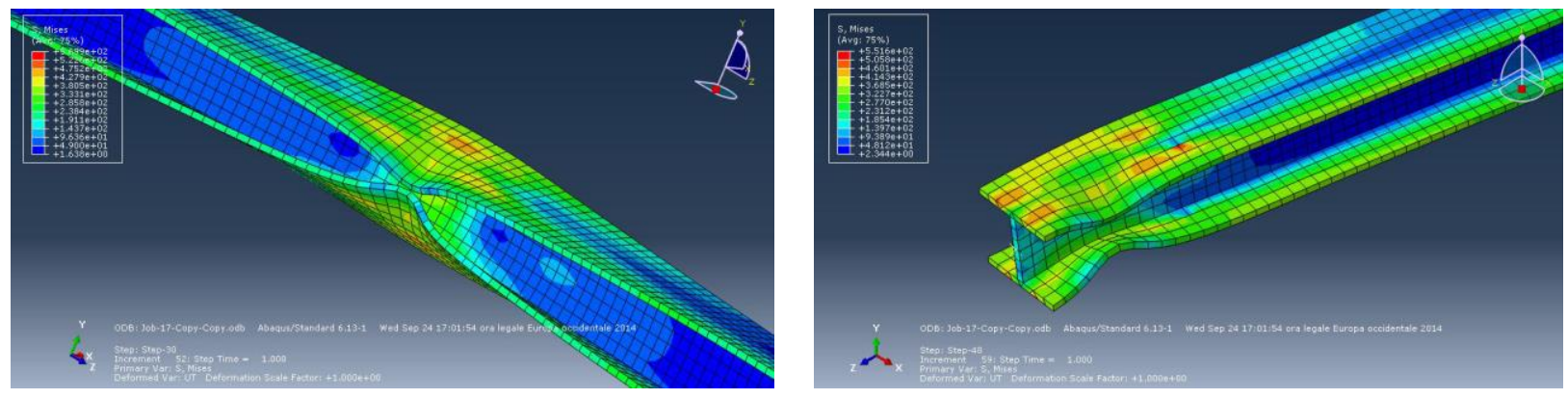

Figure 15. Local deformations at the center and end of the strut that cannot be simulated by fiber-based approach

\section{Full scale simulations}

In order to assess the accuracy of the fiber-based modelling approach in estimating the nonlinear cyclic response of full-scale braced frame configurations, two real scale frames [21][22][23] have been analysed, and the results have been compared with the results of the experiments performed on these test frames. The first numerical model (Figure 16.b) aims to capture the nonlinear behaviour of the concentrically braced steel frame tested experimentally by Metelli et. al. [21] (Figure 16.a). The beam and the columns are made of S355 steel grade with a HEB 160 profile; the two elements are connected with fixed joints while the column at the base level is restrained against horizontal and vertical displacements with pinned joints. The bracing system consists in S235 steel grade plates with a cross-section area of $20 \mathrm{~mm} \times 50 \mathrm{~mm}$, connected in the centre with a plate $200 \mathrm{~mm}$ thick and in the beam-to-column zone with bolted joints, both modelled with rigid links. The second numerical model (Figure 16.d) has been developed for a specimen that includes two different typical bracing configurations commonly used in buildings (chevron and two-storey $\mathrm{X}$ bracing), tested by Lumpkin et.al. [22][23] (Figure 16.c). Full strength and rigid beam-column joints of the test frame have been taken into account in the numerical model. In both models, rigid links have been introduced at the end of bracings in order to take into account the extra rigidity provided by the gusset plates. All beams, columns and bracings have been modelled using the fiber-based distributed plasticity approach. It should be underlined that local buckling and low-cycle fatigue effects have been kept beyond the scope of this study. 


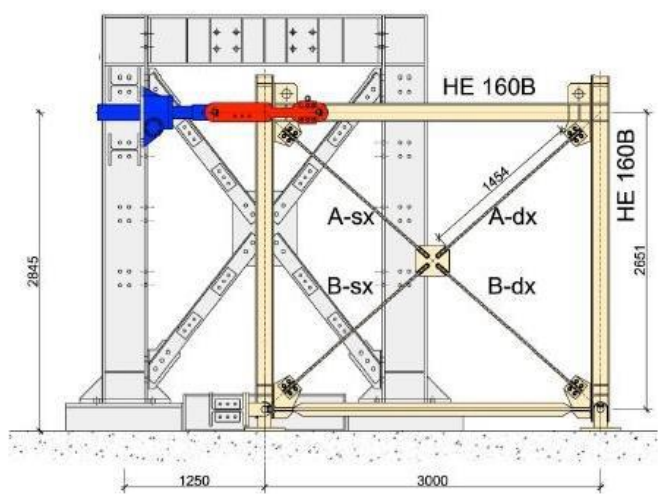

a. Full scale test specimen 1 Metelli et. al. [21]

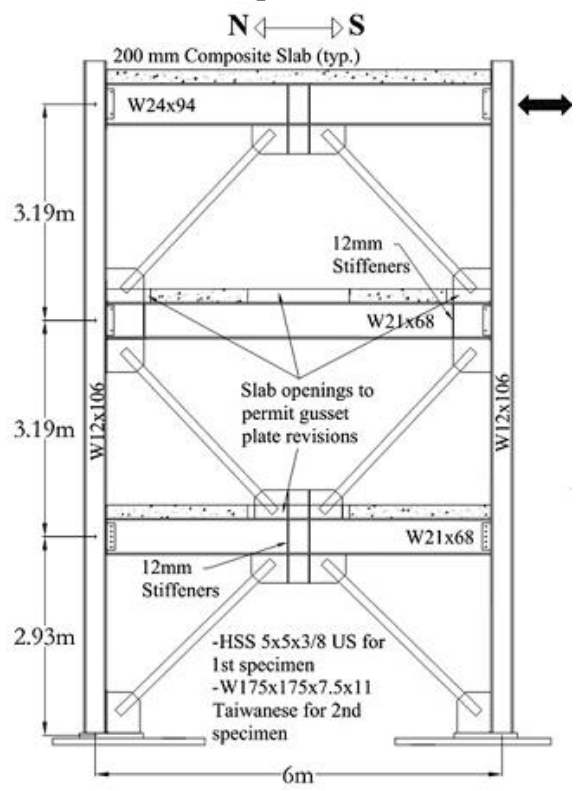

a. Full scale test specimen 2 Lumpkin et. al. [22]

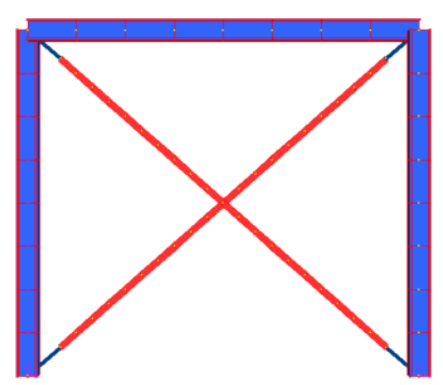

b. Numerical Model of specimen 1

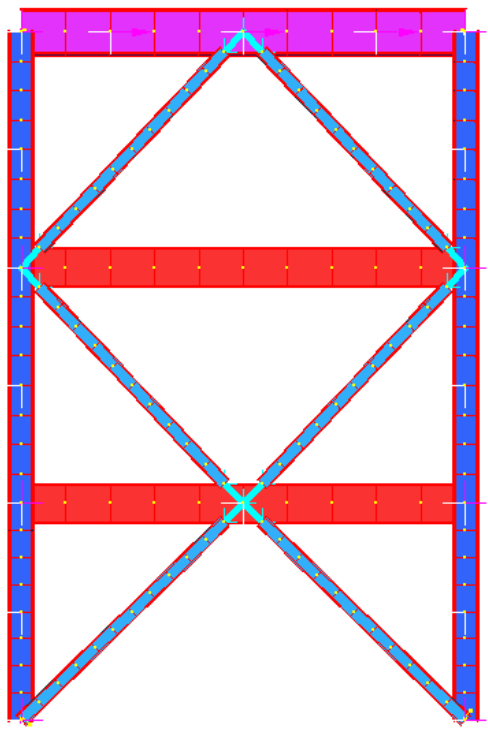

b. Numerical model of specimen 2

Figure 16. Full-scale test frame and its numerical model developed with fiber-based beam elements

Material and geometric characteristics of the test frames can be seen in Table 6. Kinematic hardening model has been used to simulate the steel material behaviour. Nominal material characteristics have been taken as reference in the first model, while the material parameters characterizing the second numerical model have been calibrated on the basis of the average stress-strain relationship derived from tensile coupon tests performed by Lumpkin [23]. An initial imperfection of $\% 0.1$ has been considered to initiate the buckling in bracing elements.

Table 6. Material properties of test specimens

\begin{tabular}{|c|c|c|c|c|c|}
\hline & & Cross section & E [Mpa] & $\mathbf{f}_{\mathrm{v}}[\mathrm{Mpa}]$ & $\mathbf{f}_{\max }[\mathrm{Mpa}]$ \\
\hline \multirow{2}{*}{$\begin{array}{c}\text { First Model } \\
\text { (Metelli et. al.) }\end{array}$} & Columns and beams & HEB160 & 210000 & 355 & 510 \\
\hline & Bracings & Rectangular plates $20 \times 50 \mathrm{~mm}$ & 210000 & 235 & 360 \\
\hline \multirow{4}{*}{$\begin{array}{c}\text { Second model } \\
\text { (Lumpkin et. al.) }\end{array}$} & Columns & $\mathrm{W} 12 \mathrm{X} 106$ & 200637 & 401 & 512 \\
\hline & Beam $-1^{\text {st }}$ and $2^{\text {nd }}$ floor & W21X68 & 216151 & 432 & 548 \\
\hline & Beam $-3^{\text {rd }}$ floor & W24X84 & 208222 & 416 & 538 \\
\hline & Bracings & W175X175x7.5x11 & 168922 & 338 & 469 \\
\hline
\end{tabular}

Nonlinear cyclic analysis has been performed imposing a cyclic displacement load on the top left node of the frames, which reproduced the loading history applied in the experimental tests (Figure 16). In the analysis, large displacements and material inelasticity have been considered, and loads have been applied as increments, ensuring the equilibrium of the internal member forces and global base shear at each step. 


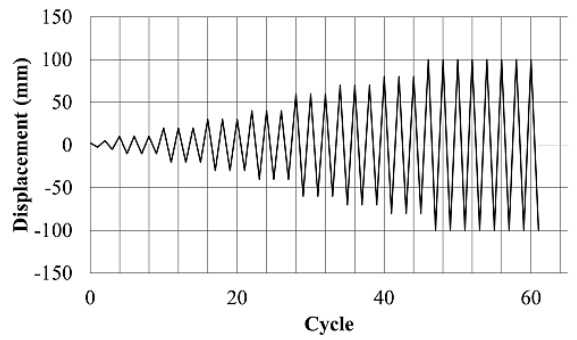

a. Loading history of Specimen 1

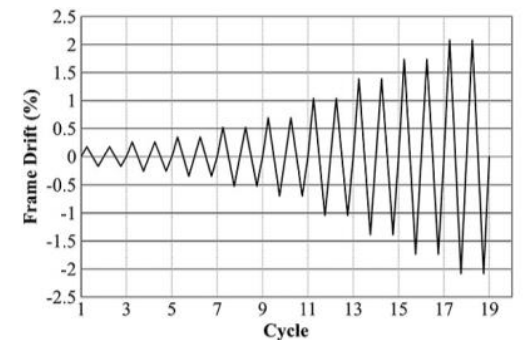

b. Loading history of Specimen 2

Figure 17. Cyclic loading history of the specimens

Figure 18 shows the comparison between the experimental and numerical results in terms of global forcedisplacement hysteresis curve for both models. A good overlap between numerical and experimental curves verifies the capability of the numerical models developed with fiber-based beam elements in simulating the hysteresis behaviour of the full scale braced test frame. It can be observed that in the first model, where the slenderness of bracings are very high, curves fit much better than the second model, in which slight differences can be observed particularly at high displacement demands, due to the damage in connections and local buckling phenomena. These results also confirm the efficiency of fiber-based modelling approach in predicting the inelastic hysteresis behaviour of the steel bracings.

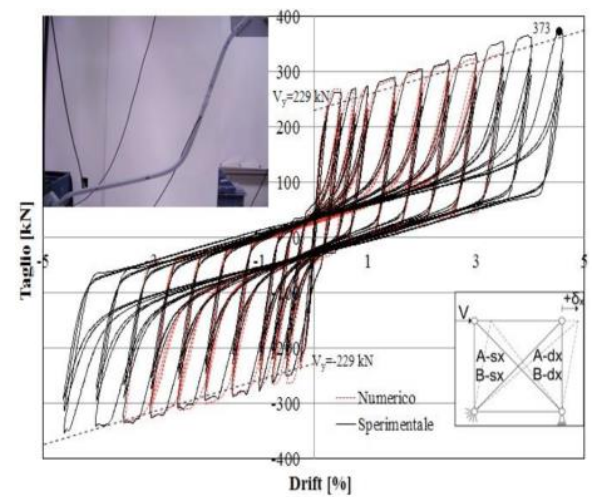

a. Experimental hysteresis curve of the first specimen

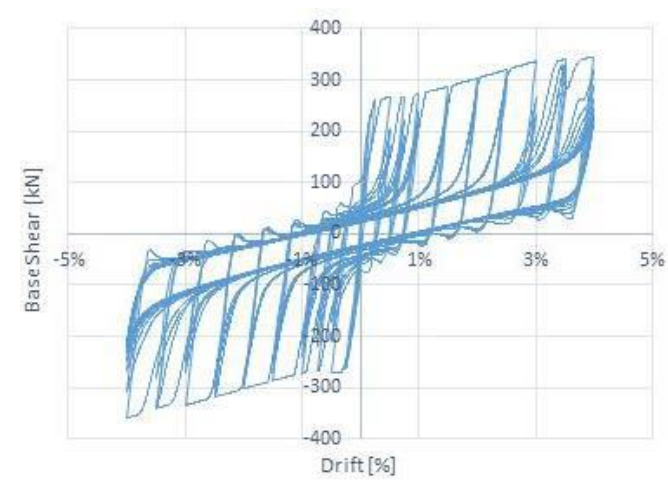

b. Numerical hysteresis curve of the first specimen

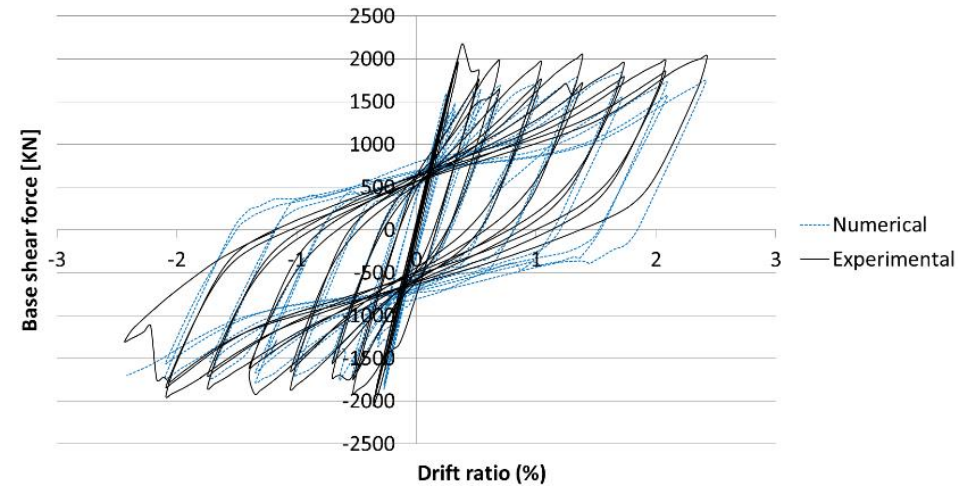

a. Numerical and experimental hysteresis curves of the second specimen

Figure 18. Cyclic loading input and hysteresis diagrams of full-scale tests and numerical analysis

\section{Conclusions}

Seismic response of a concentrically braced frame mainly depends on the behaviour of its bracing elements. An accurate numerical simulation of inelastic behaviour of a braced frame is a complex matter, for which specific tools and methods are needed. The focus of this study was to validate an accurate and time efficient way modelling approach for the simulation of steel bracings under inelastic cyclic and seismic loading, which can be used in the modelling of multi-storey structures. Therefore, a comparative numerical study has been presented to validate the suitability of fiber based distributed plasticity modelling approach, to simulate inelastic cyclic response of bracing elements. The simulations are based on previous experimental data and refined finite element models.

The comparison of the hysteresis curves of several elements, evaluated for different boundary conditions shows that results obtained by fiber-based approach are almost coincident with those obtained by continuum based modelling. This observation has been also confirmed with the full scale simulations of two different real scale test specimens. The 
only drawback is that fiber-based modelling approach is not capable of obtaining local effects. This should be carefully considered, especially when the slenderness of bracings are low. On the other hand, for a global analysis of a multi-storey building with slender bracings, the accuracy obtained without considering these local effects may be acceptable.

\section{Acknowledgment}

This study has been realized thanks to the research fund received from European commission with the contract MEAKADO RFSR-CT-2013-00022 [23][24][25][26].

\section{References}

[1] S. Salawdeh, Seismic Design of Concentrically Braced Steel Frames. PhD thesis, National University of Ireland, Galway (NUI Galway), (2012)

[2] Sze, K. Y. "Three - dimensional continuum finite element models for plate/shell analysis." Progress in Structural Engineering and Materials 4, no. 4 (2002): 400-407.

[3] Ramin, Keyvan, and Mitra Fereidoonfar. "Finite Element Modeling and Nonlinear Analysis for Seismic Assessment of OffDiagonal Steel Braced RC Frame." International Journal of Concrete Structures and Materials 9, no. 1 (2015): 89-118.

[4] Shaback. B. "HSS brace behaviour under cyclic loading." M.S. Thesis, Department of Civil Engineering, University of Calgary, Calgary, Alberta, (2001): 49-100

[5] Astaneh-Asl, Abolhassan, Subhash C. Goel, and Robert D. Hanson. "Cyclic out-of-plane buckling of double-angle bracing." Journal of structural Engineering 111, no. 5 (1985): 1135-1153.

[6] Sabelli, Rafael. Research on improving the design and analysis of earthquake-resistant steel-braced frames. EERI, 2001.

[7] Avery, Philip, and Mahen Mahendran. "Distributed plasticity analysis of steel frame structures comprising non-compact sections." Engineering Structures 22, no. 8 (2000): 901-919.

[8] Uriz, P., and S. A. Mahin. "Toward earthquake-resistant design of concentrically braced steel-frame structures. PEER rep no. 2008/08. Pacific Earthquake Engineering Research Center, College of Engineering." Univ. of California, Berkeley (2008).

[9] Nguyen, Phu-Cuong, and Seung-Eock Kim. "Distributed plasticity approach for time-history analysis of steel frames including nonlinear connections." Journal of Constructional Steel Research 100 (2014): 36-49.

[10] A. Kanyilmaz, C.A. Castiglioni, Performance of Multi-level moment resisting composite frames with dissipative devices, COMPDYN 2015, 5th ECCOMAS Thematic Conference on Computational Methods in Structural Dynamics and Earthquake Engineering, Crete Island, Greece, (2015).

[11] A. Kanyilmaz, C.A. Castiglioni, H. Degèe, P.O. Martin, A Preliminary assessment of slenderness and overstrength homogeneity criteria used in the design of concentrically braced steel frames in moderate seismicity, COMPDYN 2015, $5^{\text {th }}$ ECCOMAS Thematic Conference on Computational Methods in Structural Dynamics and Earthquake Engineering, Crete Island, Greece, (2015).

[12] L. Chen, L. Tirca, Simulating the Seismic Response of Concentrically Braced Frames Using Physical Theory Brace Models, Open Journal of Civil Engineering, (2013), 3, 69-81.

[13] Pillai, U.S., 1974. Beam-columns of hollow structural sections. Canadian Journal of Civil Engineering, 1(2), pp.194-198.

[14] Wijesundara, K. K., R. Nascimbene, and G. A. Rassati. "Modeling of different bracing configurations in multi-storey concentrically braced frames using a fiber-beam based approach." Journal of Constructional Steel Research 101 (2014): 426436 .

[15] G+D Computing Pty Limited, Straus7. Theoretical Manual. Sydney (Australia), 2004

[16] Goggins, J. M., Brian Michael Broderick, A. Y. Elghazouli, and A. S. Lucas. "Behaviour of tubular steel members under cyclic axial loading." Journal of Constructional Steel Research 62, no. 1 (2006): 121-131.

[17] ECCS (1986), Technical Committee 1. Structural Safety and Loadings -Technical Working Group 1.3. Seismic design recommended testing procedure for assessing the behaviour of structural steel elements under cyclic loads, 1st ed. Brussels

[18] ABAQUS. Analysis User's Manual. Version 6.12 ABAQUS, Inc., Dassault.

[19] Bate and Wilson, Analysis of the Bauschinger effect, Acta Met., 34 (6) (1986), pp. 1097-1105

[20] EN 1998-1-1 Design of structures for earthquake resistance (2005) 
[21] Metelli, G., Bregoli, G. and Marchina, E., 'Il comportamento isteretico di controventi concentrici realizzati con piatti', Articolo tratto dagli Atti del XV Convegno ANDIS, (2013)

[22] Lumpkin, Eric J. "Enhanced seismic performance of multi-story special concentrically brace frames using a balanced design procedure." PhD diss., University of Washington, 2009.

[23] Lumpkin, Eric J., Po-Chien Hsiao, Charles W. Roeder, Dawn E. Lehman, Ching-Yi Tsai, An-Chien Wu, Chih-Yu Wei, and Keh-Chyuan Tsai. "Investigation of the seismic response of three-story special concentrically braced frames." Journal of Constructional Steel Research 77 (2012): 131-144.

[24] H. Degee, C.A. Castiglioni, P.O. Martin, I. Calderon, B. Hoffmeister, Eight International Conference on Advances in Steel Structures, Lisbon, Portugal, (2015).

[25] I. Calderón, A. Aramburu, MEAKADO project: Design of steel and composite structures with limited ductility requirements for optimized performances in moderate earthquake areas, Steel Earth workshop, Steel based applications in earthquake prone areas, 28.10.2015

[26] H. Degee, Dimensionnement des structures métalliques et mixtes en vue d'une optimisation de leur performance en zones de sismicité faible à modérée - le projet Européen Meakado, AFPS2015 : 9ème Colloque National - Anticiper, limiter et gérer les effets des séismes dans les territoires 